\title{
BMJ Open Predictors of intentions to quit smoking in Aboriginal tobacco smokers of reproductive age in regional New South Wales (NSW), Australia: quantitative and qualitative findings of a cross-sectional survey
}

\author{
Gillian Sandra Gould, ${ }^{1,2}$ Kerrianne Watt, ${ }^{3}$ Andy McEwen, ${ }^{4}$ Yvonne Cadet-James, ${ }^{5}$ \\ Alan R Clough ${ }^{6}$
}

To cite: Gould GS, Watt K, McEwen A, et al. Predictors of intentions to quit smoking in Aboriginal tobacco smokers of reproductive age in regional New South Wales (NSW), Australia: quantitative and qualitative findings of a cross-sectional survey. BMJ Open 2015;5:e007020. doi:10.1136/bmjopen-2014007020

- Prepublication history and additional material is available. To view please visit the journal (http://dx.doi.org/ 10.1136/bmjopen-2014007020).

Received 28 October 2014 Revised 9 February 2015 Accepted 17 February 2015

\section{CrossMark}

For numbered affiliations see end of article.

Correspondene to Dr Gillian Sandra Gould; gillian.gould@newcastle.edu. au

\section{ABSTRACT}

Objectives: To assess the predictors of intentions to quit smoking in a community sample of Aboriginal smokers of reproductive age, in whom smoking prevalence is slow to decline.

Design, setting and participants: A cross-sectional survey involved 121 Aboriginal smokers, aged 18-45 years from January to May 2014, interviewed at community events on the Mid-North Coast NSW.

Qualitative and quantitative data were collected on smoking and quitting attitudes, behaviours and home smoking rules. Perceived efficacy for quitting, and perceived threat from smoking, were uniquely assessed with a validated Risk Behaviour Diagnosis (RBD) Scale.

Main outcome measures: Logistic regression explored the impact of perceived efficacy, perceived threat and consulting previously with a doctor or health professional (HP) on self-reported intentions to quit smoking, controlling for potential confounders, that is, protection responses and fear control responses, home smoking rules, gender and age. Participants' comments regarding smoking and quitting were investigated via inductive analysis, with the assistance of Aboriginal researchers.

Results: Two-thirds of smokers intended to quit within 3 months. Perceived efficacy (OR=4.8; $95 \% \mathrm{Cl} 1.78$ to 12.93) and consulting previously with a doctor/HP about quitting (OR=3.82; $95 \% \mathrm{Cl} 1.43$ to 10.2 ) were significant predictors of intentions to quit. 'Smoking is not doing harm right now' was inversely associated with quit intentions ( $\mathrm{OR}=0.25 ; 95 \% \mathrm{Cl} 0.08$ to 0.8 ). Among those who reported making a quit attempt, after consulting with a doctor/HP, 40\% (22/60) rated the professional support received as low $(0-2 / 10)$. Qualitative themes were: the negatives of smoking (ie, disgust, regret, dependence and stigma), health effects and awareness, quitting, denial, 'smoking helps me cope' and social aspects of smoking.

Conclusions: Perceived efficacy and consulting with a doctor/HP about quitting may be important predictors of intentions to quit smoking in Aboriginal smokers of reproductive age. Professional support was generally
Strengths and limitations of this study

- A novel approach to tobacco research in this population included the Risk Behaviour Diagnosis Scale to examine the predictors of intentions to quit smoking.

- High response rate and recruitment in a wide variety of community settings, using face-to-face interviews, which accommodated for participants with low literacy and allowed for participants' responses to open-ended questions.

- As a small sample in one region, findings may not apply to Indigenous peoples of diverse regions and nations.

- High level of perceived threat in the sample obscured interpretation in those with lower threat levels.

- Longitudinal research is required to determine if these and other predictors hold true for quitting success. [Terminology. We refer to the study population as Aboriginal as these are the First Nation people of NSW. When we use the term Indigenous Australians, it applies to Indigenous peoples of Australia in general, which comprises two distinct populations, Aboriginal and Torres Strait Islanders.]

perceived to be low; thus, it could be improved for these Aboriginal smokers. Aboriginal participants expressed strong sentiments about smoking and quitting.

\section{INTRODUCTION}

Tobacco smoking is established as a major contributor to the health gap for Indigenous Australian smokers, representing $12 \%$ of the burden of disease, and $17 \%$ of the preventable risk factors. 'Closing the Gap' strategies aim to halve the Indigenous smoking prevalence by $2018 .^{2}$ Indigenous smoking prevalence has slowly reduced over the past decade, but daily 
smoking is over three times the rate of the general population at $42 \%,{ }^{3}$ compared with $13 \%{ }^{4}$ Some Indigenous subgroups demonstrate no significant prevalence change for daily smoking, such as the 25-34-year-olds $(51.5 \%)$ and smokers in more remote communities. ${ }^{3}$ Overall, the remote Indigenous smoking rates are 50.4\% compared with non-remote smoking rates of $39.1 \%$; and higher for each reproductive age group: 18-24 years $59.4 \%$ versus $38.2 \%$; $25-34$ years $59.5 \%$ versus $49 \%$; $35-44$ years $55 \%$ versus $46.3 \% .^{3}$

A research focus on smokers of reproductive ages is important as women and men in these age groups are likely to have contact with unborn babies and children. Parental smoking exposes babies and children to the toxic effects of environmental and inter-uterine metabolites from tobacco smoke, contributing to prenatal and birthing risks, low birth weight and developmental problems. ${ }^{5-8}$ Parental smoking influences smoking initiation in adolescence. ${ }^{9}$ Additionally, through prenatal exposure, children born to mothers who smoke are more likely to become smokers themselves. ${ }^{10}$ Smoking can reduce fertility (in both genders), and increases maternal birthing risks. ${ }^{11}$ Quitting smoking is also important as early as possible in the reproductive years, because after 40 years of age life expectancy reduces by 3 months for every year of smoking. ${ }^{12}$

Australia is a world leader in tobacco control with effective policies spanning mass media interventions, smoke-free environments, pricing and plain packaging, resulting in the sixth lowest Organisation for Economic Cooperation and Development (OECD) national prevalence. ${ }^{13}$ This success has not yet translated into the same level of improvement for Australia's vulnerable First Nations peoples, despite an evaluation of the targeted 'Break The Chain' campaign reporting 23\% of Indigenous Australians trying to quit smoking, ${ }^{14}$ and an increase in funded Indigenous tobacco control programmes. ${ }^{15}$

Having an intention to quit smoking is an important step that precedes making a quit attempt according to health behaviour theories. ${ }^{16}$ However, intentions can also be precipitated by changes in health status or impromptu evaluations. ${ }^{17}$ International Tobacco Control (ITC) studies enable cross-country comparisons of predictors of intentions to quit and smoking cessation. Predictors vary with culture, but commonly include gender, age, nicotine dependence, motivational factors, health concerns, self-efficacy and past quit attempts and are useful to guide clinical practice. ${ }^{18} \mathrm{~A}$ meta-analysis revealed that past quitting behaviour and motivation to stop smoking are highly predictive of quit attempts, but the predictors of cessation are more associated with nicotine dependence. ${ }^{19}$ Although an ITC-related project is underway for Indigenous Australian smokers,${ }^{20}$ to date there has been limited research to explore the predictors of intentions to quit smoking, quit attempts or cessation in Indigenous Australians.

This study on Aboriginal smokers of reproductive age in a regional area of NSW examined the predictors of intentions to quit smoking, in the context of demographic variables, smoking and past quitting behaviours, using a published study protocol. ${ }^{21}$ We included variables from the validated Risk Behaviour Diagnosis (RBD) Scale as potential predictors of intentions to quit smoking. ${ }^{22}$ The RBD Scale, based on the Extended Parallel Process Model (EPPM), assesses the relative levels of perceived threat (severity and susceptibility to the health threats from smoking) and perceived efficacy (self-efficacy and response efficacy). Quantitative findings were complemented by an analysis of participants' comments about smoking and quitting. These data can be used to inform policies and practice. Furthermore, we were interested in the experiences of participants in consulting with their doctor about quitting, and the level of support they received.

\section{METHODS}

A brief summary is given below of the methods already published. ${ }^{21}$ This analysis was part of a larger study in the same sample. ${ }^{21} 22$

\section{Participants and setting}

From January to May 2014, Aboriginal smokers $(\mathrm{N}=121)$, aged 18-45 years old, were recruited by personal intercept at a range of community events on the Mid-North Coast NSW, including Aboriginal cultural events, health days and sports events. We used quota sampling by age and gender to represent the target population as closely as possible, as a random sample was unfeasible. We estimated the response rate of participants during the first half of the recruitment, before reaching the age/gender quotas, by keeping a tally of how many were eligible/ ineligible (selection criteria-self-identified as Aboriginal or Torres Strait Islander, aged 18-45, current smoker) and those who agreed to participate. A 20-30 min survey was conducted with each participant by author GG, or either a male or female Aboriginal research assistant, using a tablet computer or on paper.

\section{Data collection}

Data were collected on demographics, smoking and quitting attitudes and behaviours, age of smoking initiation, home smoking rules, consulting history about quitting and professional support for quitting.

Key variables for this analysis were measured with Likert scales as detailed below. Two of these (perceived threat and efficacy) are from the RBD Scale and measure attitudes to health risks from smoking, and the belief in one's own ability to quit and the value of quitting. Efficacy has central importance in behaviour change according to social cognitive theory. ${ }^{23}$ Intentions to quit are from a validated scale used by Wong and Cappella $^{24}$ to assess a time-related motivational intention, and the protection response and fear control response scales were validated by Gould $e t a l^{22}$ to assess attitudes to protecting others from smoking, and 
potential dis-engagement with health messages. For further details of the questions and scales, see the online supplementary table.

1. Perceived threat from smoking (five items): susceptibility and severity of the threat from smoking

2. Perceived efficacy (five items): self-efficacy and response efficacy-that is, belief in one's ability to quit, and that quitting will make a difference to health risks

3. Intentions to quit smoking in the next 3 months (five items): based on a previous study ${ }^{24}$

4. A protection response scale (four items): attitudes about pregnant women smoking, partners' smoking, smoking around children and Indigenous smoking in general

5. A fear control response scale (four items): denial, avoidance, derogation of messages and reactance.

The mean score for each scale was obtained and then categorised into high versus low (median split).

Home smoking rules were assessed by a multichoice question offering four options, then recoded into complete ban versus partial/no ban. Having a baby/child at home, consulting history with a doctor or other HP (such as a nurse or an Aboriginal Health Worker) about quitting, and previous quit attempts (currently/in the past) were measured by yes/no options. Previous quit attempts was a filter question for asking further information about quitting, that is, the use of quit medications and the support available from a doctor/HP on their previous/ current attempt (on a sliding scale from 0 to 10).

Provision was made to document qualitative responses in several open-ended sections of the questionnaire. Qualitative data were collected during the interviews as follows: at the start when participants were asked what they thought about smoking in general; to elicit more information from those who said they did not want to quit smoking; and at the end in case the participants wanted to provide any further information. Notes were taken by the interviewer to approximate the participant's comments as closely as possible, on a computer tablet or paper survey.

\section{Analysis}

SPSS V.20 was used to conduct quantitative analyses. $\chi^{2}$ tests were used to explore associations between predictor variables and intentions to quit smoking. Clustering effects were determined by examining cross-associations between variables. A visual modelling exercise demonstrated multiple associations (see figure 1).

Binary logistic regression was used to identify the independent predictors of intention to quit smoking. Variables that were significant in crude analyses, on the likelihood of having an intention to quit smoking, were entered into the model and removed one at a time. If the ORs of the remaining variables changed by more than $10 \%$, the variable was retained.

Qualitative data were collated across the surveys, initially male and female separately and then combined.
A general inductive methodology (comprising a five-step process of close reading of the text, identifying segments of information, coding information and labelling categories/themes, reducing overlap of categories/themes, and creating a model of the most important categories/ themes) was used to draw emergent themes from the data. ${ }^{25}$ The data were independently open-coded and grouped by three researchers (GG and two Aboriginal research assistants, EJW and SJ) to maximise reliability (investigator triangulation). ${ }^{26}$ We did not use any predefined themes in the analysis. Following this initial process, we used a collaborative approach to refine and name the emergent themes and subcategories based on discussions between the team members, privileging the interpretation by the Aboriginal members of the team. This collaborative approach was based on the analysis we used for a previous study, ${ }^{27}$ while taking into account reflexivity through the members of the team questioning their own and each other's assumptions.

\section{RESULTS}

The response rate for the survey (those who agreed as a proportion of those who were eligible) was $89 \%$. Characteristics of participants are shown in table 1. Over three-quarters of participants were assessed as having high perceived threat, only half of the participants had high perceived efficacy on the RBD Scale, and $66 \%$ had a high-level intention to quit smoking in the next 3 months. Sixty-seven per cent $(n=81)$ reported having a baby/child at home. Complete home smoking bans were reported by $79 \% \quad(n=96)$. This was significantly comprised of $86 \%(\mathrm{n}=70)$ with a baby/child at home versus $65 \%(\mathrm{n}=26)$ with no baby/child at home $\left(\chi^{2}=7.5\right.$; $\mathrm{df}=1 ; \mathrm{p}<0.01)$.

We found that $52 \% \quad(n=63)$ had consulted with a doctor/HP about quitting smoking. Eighty per cent $(n=97)$ of participants reported making a previous quit attempt: among these, $11 \%(\mathrm{n}=11)$ were currently trying to quit or reduce smoking. Nearly half of those reporting quit attempts had tried to quit in the past year; however, $54 \%(n=52)$ had never tried smoking cessation medications. The median level of reported support available to those who had consulted a doctor or HP on their previous/current quit attempt $(n=60)$ was 4 of 10 (IQR 1-8). However, 40\% $(n=24)$ rated the support available to them as very low, in the range of $0-2$, out of a possible score of 10 .

\section{Predictors of intention to quit}

Table 2 shows the results of the binary logistic regression (unadjusted and adjusted). Two sets of variables were considered multicollinear. These were 'home smoking rules' and 'having a baby/child at home', and 'consulted a doctor/HP about quitting (currently/in the past)' and 'previous/current quit attempts'. In each of these instances, one of the variables was removed from the model after discussion with all authors. 


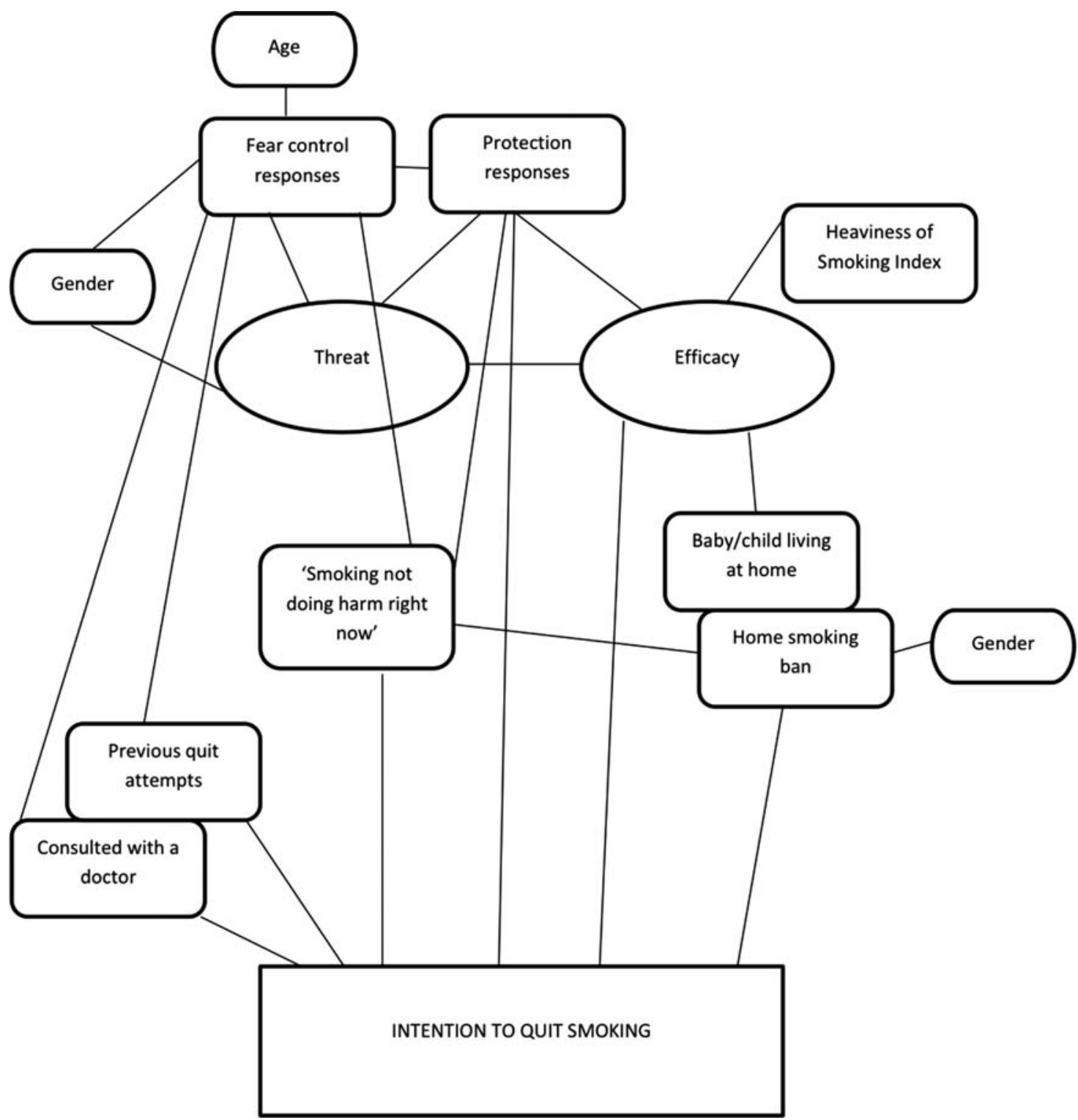

Figure 1 Correspondences in the non-adjusted model of predictors of intentions to quit smoking in Aboriginal smokers aged 18-45 years in New South Wales.

After adjusting for the effect of confounding, significant independent predictors of intentions to quit smoking in the next 3 months were: high perceived efficacy and "previously consulted with doctor or HP about quitting'. In addition, the attitude that 'smoking is not doing me any serious harm at the moment' was inversely associated with intentions to quit. Confounders were home smoking rules, protection responses and fear control responses. High perceived threat was inversely associated with intention to quit, but not significantly $(\mathrm{OR}=0.31 ; 95 \%$ CI 0.09 to 1.05$)$. Gender, age and Heaviness of Smoking Index were not confounders and were not included in the model. The model explained $38 \%$ (Nagelkerke $\mathrm{R}^{2}$ ) of the variance in intentions to quit smoking and correctly classified $80 \%$ of cases.

We attempted to assess an interactive effect of threat on efficacy in the model, as an interactive element was suggested when we validated the RBD Scale and the
EPPM. ${ }^{22}$ When the results were stratified for threat, the same associations were observed for participants in the high threat category, but there were too few participants in the low threat category for the logistic regression to be meaningful (results not shown).

\section{Qualitative findings}

Five main themes emerged from the qualitative analysis, namely: negatives about smoking, health effects, quitting, denial, social aspects and 'smoking helps me cope'. Themes, subcategories and representative examples of the comments made by participants are depicted in table 3. The following subcategories were most frequently communicated by the 121 participants in the open-ended sections: stress was expressed 45 times (women 29, men 16), dependence on smoking 44 times (women 21, men 23) and disgust 39 times (women 22, men 17). Several indicated that the survey had raised 
Table 1 Characteristics of 121 participants from the Mid-North Coast, New South Wales

\begin{tabular}{|c|c|}
\hline Characteristic & $\mathbf{N}(\%)$ \\
\hline Male & $58(48)$ \\
\hline Female & $63(52)$ \\
\hline \multicolumn{2}{|l|}{ Age group (years) } \\
\hline $18-24$ & $36(30)$ \\
\hline 25-34 & $41(34)$ \\
\hline $35-45$ & $44(36)$ \\
\hline \multicolumn{2}{|l|}{ Main income source ( $\mathrm{n}=1$ missing) } \\
\hline Income support & $79(65)$ \\
\hline Working & $41(34)$ \\
\hline Healthcare card holder & $90(74)$ \\
\hline \multicolumn{2}{|c|}{ SEIFA* deciles of postcodes ( $n=2$ missing) } \\
\hline $1-2$ & $73(60)$ \\
\hline $3-4$ & $40(33)$ \\
\hline $5-9$ & $6(5)$ \\
\hline \multicolumn{2}{|l|}{ Education level } \\
\hline Primary to year 10 & $56(46)$ \\
\hline Year 11 to year 12 & $30(35)$ \\
\hline Postsecondary & $35(29)$ \\
\hline Baby/child at home & $81(67)$ \\
\hline \multicolumn{2}{|l|}{ Smokers at home (includes self) } \\
\hline 1 & $38(31)$ \\
\hline $2-3$ & $71(59)$ \\
\hline$>3$ & $12(10)$ \\
\hline \multicolumn{2}{|l|}{ Home smoking rules } \\
\hline Complete ban & $96(79)$ \\
\hline $\begin{array}{l}\text { Smoke-free homes with } \\
\text { children }\end{array}$ & $70(86)$ \\
\hline $\begin{array}{l}\text { Smoke-free homes with no } \\
\text { children }\end{array}$ & $26(65)$ \\
\hline Partial/no ban & $25(21)$ \\
\hline $\begin{array}{l}\text { Most of the family/social circle } \\
\text { smoke }\end{array}$ & $101(84)$ \\
\hline \multicolumn{2}{|l|}{ Frequency of smoking } \\
\hline Daily smoker & $102(84)$ \\
\hline Smoke most days & $8(7)$ \\
\hline Occasional smoker & $11(9)$ \\
\hline \multicolumn{2}{|l|}{ Type of tobacco smoked } \\
\hline Normal cigarettes & $110(91)$ \\
\hline Hand-rolled cigarettes & $51(42)$ \\
\hline Smoking behaviours & Mean; $\pm S D ;$ (range) \\
\hline Age of first cigarette & $13.98 ; \pm 2.99 ;(5-25)$ \\
\hline Age took up regular smoking & $16.11 ; \pm 3.05 ;(7-27)$ \\
\hline $\begin{array}{l}\text { Duration (years) until regular } \\
\text { smoker }\end{array}$ & $2 ; 0.3 ;(0-11)$ \\
\hline Total years of regular smoking & 15; 8.22; (1-32) \\
\hline $\begin{array}{l}\text { Heaviness of Smoking Index } \\
(0-6)\end{array}$ & Median: 3 (IQR 2-4) \\
\hline \multicolumn{2}{|l|}{ Quitting behaviours } \\
\hline Previous quit attempts & $97(80)$ \\
\hline $\begin{array}{l}\text { Consulted with doctor/HP about } \\
\text { quitting }\end{array}$ & $63(52)$ \\
\hline Used cessation medications & $69(46)$ \\
\hline \multicolumn{2}{|l|}{ Variables from scales } \\
\hline \multicolumn{2}{|l|}{ Perceived efficacy } \\
\hline High & $63(52)$ \\
\hline Low & $58(48)$ \\
\hline
\end{tabular}

Table 1 Continued

\begin{tabular}{lc}
\hline Characteristic & N (\%) \\
\hline Perceived threat & $93(77)$ \\
High & $28(23)$ \\
Low & \\
Protection responses & $84(69)$ \\
High & $37(31)$ \\
Low & $63(52)$ \\
Fear control responses & $58(48)$ \\
High & $80(66)$ \\
Low & $41(34)$ \\
Intention to quit smoking in next 3 months \\
High \\
Low \\
Intention to seek help to quit smoking in next 3 months \\
High & $61(50)$ \\
Low & $60(50)$
\end{tabular}

Higher deciles reflect higher relative advantage; lower deciles reflect lower relative advantage. For this sample, all participants who were resident in the local area were deciles 1-4. Participants in deciles 5-9 were not local residents.

*SEIFA (Socioeconomic Index For Areas) was used to estimate socioeconomic status in this study, ${ }^{28}$ specifically the Index of

Relative Socioeconomic Advantage and Disadvantage. $\mathrm{HP}$, health professional.

their awareness about smoking, and many asked for advice and cessation assistance from the interviewers at the completion.

The qualitative findings informed some of the key variables in this study. Perceived threat went beyond physical health concerns, such as disgust, regret and concerns about stigma-these may threaten psychological wellbeing. Participants reported witnessing tobacco-related illnesses and deaths in their relatives, and were also concerned for their own health.

Perceived efficacy for quitting related to comments about willpower and the use of medications, which may aid quitting. Some reported adverse medication effects (eg, from nicotine patches) and/or being told that quit medications were not suitable for them (eg, varenicline). Stress and dependence were cited as barriers to quitting. When being asked questions about response efficacy for quitting, a few women held the perception that quitting smoking could bring on serious diseases as they had seen elders succumb to cancer after quitting.

Protection responses were illustrated by comments about protecting children and babies from tobacco smoke, concerns about children taking up smoking and wanting to be a good role model for children. Those who said smoking was 'not a problem', or they did not think much about their smoking illustrated fear control responses. Some of the younger men gave the impression that they were 'bullet-proof'. ${ }^{29}$

Many volunteered at the first question that they wanted to quit smoking, thus indicating an intention to stop. Reasons given for not wanting to quit were mainly stress and enjoyment (mostly by women), and dependence (mostly by men). 
Table 2 Association between variables and intentions to quit smokingt in 120 Aboriginal smokers aged $18-45$ years from the Mid-North Coast, New South Wales, Australia

\begin{tabular}{|c|c|c|c|}
\hline Variables in the model & $\mathbf{N}$ & Unadjusted OR (95\% Cl) & Adjusted OR (95\% Cl)‡ \\
\hline \multicolumn{4}{|l|}{ Predictors } \\
\hline High perceived efficacy & 63 & $3.59(1.62 \text { to } 7.98)^{\star \star}$ & $4.8(1.78 \text { to } 12.93)^{\star \star}$ \\
\hline Consulted with a doctor/HP currently/previously & 63 & $4.26(1.89 \text { to } 10)^{\star \star \star}$ & $3.82(1.43 \text { to } 10.2)^{\star \star}$ \\
\hline 'Smoking is not doing me harm right now' & 24 & $0.17(0.06 \text { to } 0.44)^{* * *}$ & $0.25(0.08 \text { to } 0.8)^{*}$ \\
\hline \multicolumn{4}{|l|}{ Confounders } \\
\hline High perceived threat & 93 & $0.73(0.29$ to 1.83$)$ & $0.31(0.09$ to 1.05$)$ \\
\hline Protection responses & 84 & $2.97(1.33 \text { to } 6.67)^{\star \star}$ & 1.35 (0.44 to 4.12$)$ \\
\hline Fear control responses (denial, etc) & 62 & $0.36(1.16 \text { to } 0.8)^{*}$ & 0.65 (0.24 to 1.78$)$ \\
\hline Complete home smoking ban & 95 & 2.13 (0.87 to 5.26$)$ & $1.67(0.55$ to 5.11$)$ \\
\hline \multicolumn{4}{|l|}{ Variables in model not confounders } \\
\hline Gender-Male & 58 & $0.66(0.24$ to 1.81$)$ & NA \\
\hline Age 18-24 & 36 & 1.0 & \\
\hline $25-34$ & 41 & $1.16(0.34$ to 3.96$)$ & NA \\
\hline $35-45$ & 44 & 0.96 (0.27 to 3.36$)$ & NA \\
\hline Heaviness of Smoking Index & & 0.91 (0.27 to 3.36$)$ & NA \\
\hline
\end{tabular}

\section{DISCUSSION}

We examined the predictors of intentions to quit in a community sample of Aboriginal smokers of reproductive age in regional NSW, and analysed qualitative responses to the open-ended questions in the survey. To the best of our knowledge, this is the first study to include variables from the RBD Scale as predictors of intentions to quit smoking in an Indigenous population. Perceived threat levels were high in this sample $(77 \%)$, and $79 \%$ of participants reported that home smoking bans were implemented $(86 \%$ of those with children at home), suggesting that the majority of participants were familiar with messages about smoking harms and smokefree environments. Predictors of intentions to quit smoking (in the next 3 months) included high perceived efficacy and 'previously consulted with a doctor or HP'. 'Smoking not doing harm right now' was inversely associated with intentions to quit smoking, implying a lack of immediacy of threat and/or lack of priority for quitting. Perceived threat was inversely associated with intention to quit, but the $95 \%$ CI just included 1.0. The high level of perceived threat in the sample made it difficult to analyse whether perceived threat was a confounder or an effect modifier.

Some variables, which might have been expected to be significant according to previous research, such as whether most of the participant's family/social circle smoked ${ }^{30}$ the number of smokers in the house ${ }^{30}$ or the age at first cigarette, ${ }^{31}$ were not associated with intention to quit, even in crude analyses. Neither was educational level, ${ }^{32}$ or other socioeconomic indicators, ${ }^{32}$ but this sample from a low socioeconomic region may have been too homogeneous to detect differences. However, socioeconomic disadvantage may impact on the short-term success of quit attempts. ${ }^{33}$ Although we were not able to demonstrate an interactive effect with different levels of perceived threat and efficacy on quit intentions in this study, complex interactions have been suggested by the RBD Scale validation. ${ }^{22}$

The qualitative data added richness to the quantitative findings and confirmed some of the intensity implied by the high perceived threat levels, with an emphasis on disgust and health concerns in many. Several of the qualitative themes and subcategories in this study have been previously noted in Indigenous Australian smokers, namely: the social norms and family influences of smoking, ${ }^{27} 30{ }^{34-39}$ association of smoking with alcohol intake, ${ }^{39} 40$ concerns about the health effects and the financial costs, ${ }^{35}$ protecting children from tobacco smoke, ${ }^{27} 344142$ a desire to quit smoking, ${ }^{43}{ }^{44}$ concerns about nicotine dependence, ${ }^{30} 3944$ the stigma of smoking ${ }^{27} 44$ and smoking as a stress-reliever and stress as a barrier to quitting. ${ }^{27} 30$ 34-39 414445 The exacerbation of stress when not smoking may be interpreted as an overlap with nicotine dependence and withdrawal symptoms, as described previously in this population. ${ }^{27} 46$ The importance of willpower for quitting may be allied to the concept of resilience for Indigenous smokers, which in turn can be augmented with social and professional support. ${ }^{45}$

A systematic review of studies across several vulnerable populations in high-income countries, including Indigenous peoples, reported that smoking was used as a coping mechanism, a way to deal with stressors in everyday life and a barrier to quitting. ${ }^{47}$ This review also demonstrated that historical, social and cultural norms fostered continued smoking and was a barrier to quitting within Indigenous peoples. The low ratings for HP support in our sample were also confirmed by Twyman et $a l \mathrm{~s}{ }^{47}$ systematic review, suggesting a lack of support 
Table 3 Themes, subcategories and examples of comments made in response to open-ended questions in the study with 121 Aboriginal smokers in regional New South Wales, Australia

\begin{tabular}{|c|c|c|}
\hline Theme & Subcategory & Examples \\
\hline \multirow{5}{*}{$\begin{array}{l}\text { Negatives about } \\
\text { smoking }\end{array}$} & Disgust & 'I hate it', 'horrible', 'disgusting', 'filthy dirty habit', 'shitty', 'it stinks' \\
\hline & Dependence & 'too far gone to break the habit', 'I depend on it', 'very addictive' \\
\hline & Regret & 'didn't think about what I was doing when I was younger', 'wish I never started' \\
\hline & Cost & 'very expensive', 'over paying price' \\
\hline & Stigma & 'really bad social stigma', 'fed up being told we're bad' \\
\hline \multirow[t]{3}{*}{ Health effects } & Health & $\begin{array}{l}\text { 'watched my father die from heart disease...sits in the back of your mind', 'just } \\
\text { lost my mother from cancer... don't want to end up like her' }\end{array}$ \\
\hline & Protecting others & $\begin{array}{l}\text { 'don't want to touch baby with smoking hands', government should ban } \\
\text { cigarettes, 'break the cycle' }\end{array}$ \\
\hline & Misconceptions & $\begin{array}{l}\text { 'l've seen elders give up then develop cancer', 'I'm scared quitting will cause } \\
\text { cancer' }\end{array}$ \\
\hline \multirow[t]{4}{*}{ Quitting } & Wanting to quit & 'don't want to smoke any more', 'wish I could give up', 'I'm trying to quit' \\
\hline & Willpower & 'it's a matter of willpower', 'I know my own willpower' \\
\hline & Support & 'would like to have group support, not do it alone' \\
\hline & Quit medications & $\begin{array}{l}\text { 'patches don't work for me', doctor told some that medication was unsuitable, } \\
\text { requests for further information, desire to try medication }\end{array}$ \\
\hline \multirow[t]{3}{*}{ Denial } & $\begin{array}{l}\text { Smoking is no } \\
\text { problem }\end{array}$ & $\begin{array}{l}\text { 'don't think much about it', 'not much to say about it', 'don't really see myself as } \\
\text { a smoker' }\end{array}$ \\
\hline & Quitting not a priority & $\begin{array}{l}\text { 'not worried about quitting at the moment', 'couldn't be bothered [to quit]', } \\
\text { 'smoking is a convenience' }\end{array}$ \\
\hline & Enjoyment & 'I like it, makes me feel better', 'I enjoy having a cigarette', \\
\hline \multirow[t]{2}{*}{ Social aspects } & $\begin{array}{l}\text { Social and family } \\
\text { influences }\end{array}$ & 'more of a social thing', 'doing it with the crowd', 'family all smoked' \\
\hline & Alcohol & 'a few more with drinks', 'need a smoke to go with a drink' \\
\hline \multirow[t]{4}{*}{$\begin{array}{l}\text { 'Smoking helps } \\
\text { me cope' }\end{array}$} & Stress relief & $\begin{array}{l}\text { 'gets me through the day', 'calms your nerves', 'helps me cope with stress and } \\
\text { anxiety', }\end{array}$ \\
\hline & Stress as barrier & $\begin{array}{l}\text { 'tried to give up often....but its relaxing', 'be stressed out all day [if didn't } \\
\text { smoke]' }\end{array}$ \\
\hline & Time out & 'sit and have a smoke for 5 minutes and I can think', 'time out from the kids' \\
\hline & Dealing with weight & 'that's why I restarted smoking, to loose weight [after childbirth]' \\
\hline
\end{tabular}

from health and service providers for quitting in vulnerable populations in general, including Indigenous peoples.

However, ours is the first study as far as we know to report intense expressions of disgust for smoking, and regret for starting in this Australian Indigenous population. Disgust has been linked with the moralisation of smoking, rejection and stigmatisation. ${ }^{48}$ Disgust has been reported in qualitative studies with disadvantaged smokers and non-smokers in the $\mathrm{UK}^{49}$ and young Australian women. ${ }^{50}$ Regret was reported as a near universal experience in $90 \%$ of smokers from high-income countries in the ITC study. ${ }^{51}$ Regret was associated with perceived addiction and failed quit attempts, but not with ethnicity. ${ }^{51}$

Strengths of the study were the novel approach to researching smoking in this population, the high response rate and recruitment in a wide variety of community settings, using face-to-face interviews, which accommodated for participants with low literacy and allowed for capturing the participants' responses to open-ended questions. Several limitations of this study should be noted. It was a small sample in one region, and findings may not apply to Indigenous peoples of diverse regions and nations. As with any such research, selection and information bias may be operant (the survey relied on self-report). By limiting the study to current smokers, we were not able to assess how ex-smokers perceived professional support for quitting. The qualitative data relied on documenting the participant's comments on the computer tablet or paper survey, rather than audio recording and transcribing the dialogue. This meant the quotes were approximated. We considered that audio recording would be too intrusive for a survey of this nature.

The relevance of these findings in an Aboriginal community sample of reproductive age, where prevalence is slow to decline, is that these factors can be used to guide strategies for cessation.

\section{Implications for practice and policy}

It is important to encourage Aboriginal smokers of reproductive age to (1) make more quit attempts and (2) support those quit attempts to give smokers a better chance of success. Smokers in this age range have much to gain by reducing exposure to babies and children, and protecting their own health as quitting before age 40 is essential for maximum health benefits. ${ }^{12}$ 
Identifying those who are more likely to make a quit attempt, may enable tailoring of messages and supportive approaches. As perceived efficacy was an important predictor in this population, tobacco control messages could be strengthened with more focus on building efficacy for quitting, such as increasing motivation and vicarious achievement through real testimonials from successful quitters. ${ }^{52}$ Self-efficacy may be enhanced through acknowledging incremental success via the clinical encounter. ${ }^{23}$ Having access to evidence-based treatment will also increase perceived efficacy, and is vital for those who cannot quit unaided. A few misperceptions may need to be addressed, with some women being caught between the threat from smoking and fear of quitting as a potential instigator of cancer. Increasing knowledge and health literacy can be easily achieved through a variety of means. Capitalising on smokers' feelings of regret, if confirmed by other studies, may be possible through careful social marketing guided by Aboriginal community consultation. Regret has been a theme in some of the Indigenous 'Rewrite Your Story' social marketing campaigns. ${ }^{53}$ However, the 'pedagogy of disgust' is more controversial as a persuasive devise. ${ }^{54}$ Lupton argues that there is insufficient recognition of the unintended consequences of provoking disgust in tobacco control campaigns, as disgust can marginalise already vulnerable populations, and create disempowerment rather than choice. ${ }^{54}$

If a patient had previously consulted with a doctor/HP about quitting smoking, they were nearly four times as likely to have a time-defined intention to quit smoking, suggesting that these smokers should receive priority for further support from clinicians. The low ratings of perceived support from an HP implies that cessation approaches, the patient experience of quit support, and/ or access to services could be improved, or that the population has an unrealistic expectation of what support is available. Medical professionals have a duty to provide high quality equitable support in a culturally competent manner to all smokers. ${ }^{55}$ Qualitative research reported that positive interactions from health professionals were important to foster success for Aboriginal ex-smokers. ${ }^{44}$ One of the subtle barriers to cessation for disadvantaged smokers is service level reinforcement of smoking, or smoking being overlooked as a major priority. ${ }^{56}$

This study may inform policies and practices about how antitobacco and cessation messages could be used in regional strategies and clinical interventions for smoking cessation for Aboriginal smokers in this age range. We cautiously suggest that improvements could be achieved through clinician training, ${ }^{57}$ offering all Aboriginal smokers evidence-based management for smoking including pharmacotherapy and counselling, ${ }^{55}{ }^{58}$ personalisation of health promotion messages based on efficacy for this age-group and addressing any structure barriers for access. 4759

While the above approaches are not new, it makes good translational sense to ensure that they are consistently applied in this population. Nonetheless, few cessation interventions have been designed to enhance efficacy. ${ }^{60}$ In an Aboriginal population, like this one on the Mid-North Coast NSW, further heightening of the already high perceived threat levels may be not required, and could possibly be counterproductive. ${ }^{22}$ This study has implications therefore for regional health promotion programmes that could assess levels of threat and efficacy and on the basis of this provide tailored messages and interventions. Those with intentions to quit smoking may not change their behaviour due to the attitude-behaviour gap, so a prospective longitudinal study is required to determine if these, and other predictors, hold true for quitting success.

\section{Author affiliations}

${ }^{1}$ College of Public Health, Medical and Veterinary Sciences, James Cook University, Cairns, Queensland, Australia

${ }^{2}$ School of Medicine and Public Health, The University of Newcastle, University Drive, Callaghan, New South Wales, Australia

${ }^{3}$ College of Public Health, Medical and Veterinary Sciences, James Cook University, Townsville, Queensland, Australia

${ }^{4}$ Health Behaviour Research Centre, Epidemiology and Public Health, University College London, London, UK

${ }^{5}$ Indigenous Centre, James Cook University, Townsville, Queensland, Australia ${ }^{6}$ Australian Institute of Tropical Health and Medicine, James Cook University, Cairns, Queensland, Australia

Acknowledgements The authors acknowledge the valuable input of the Aboriginal community panel and the advice of the Aboriginal Health Worker about the questionnaire. The authors thank the partnering Aboriginal Community Controlled Health Service for supporting the study and facilitating local cultural protocols. The authors acknowledge the valuable assistance from Aboriginal research assistant E J Williams and Aboriginal research volunteer Sharne Johnson. Lastly, the authors are grateful to all the participants for sharing their experiences.

Contributors GG was responsible for the concept and design of the project, developing and adapting the survey instruments and digital format, testing the suitability of the survey for Aboriginal participants, conducting surveys, training and supervising Aboriginal research assistants, collating, analysing and interpreting results and writing the reports and manuscripts. KW contributed to the research design and statistical analysis, checked all statistical findings and critically reviewed the manuscripts. AM advised on aspects related to tobacco smoking, smoking risk behaviours and the survey, qualitative analysis and a critical review of the manuscripts. YCJ as the Aboriginal academic advisor advised on the Aboriginal community consultation processes, recruitment and the cultural interpretation of results. AC oversaw the study and advised on all aspects, including assisting with the logistic regression, advising about the presentation of results and critical reviewing all manuscript drafts. Aboriginal research assistant EJW and Aboriginal research volunteer SJ recruited and interviewed participants and contributed to the qualitative data analysis and its interpretation.

Funding This work was supported by the: National Health and Medical Research Council (Australia) and National Heart Foundation (Australia) postgraduate scholarship for Indigenous health research (GG)—APP1039759/ PP 11S 6181; National Health and Medical Research Council Career Development Award (AC)—APP1046773; Royal Australian College of General Practitioners and Australian Primary Health Care Research Institute Indigenous Health Award 2013; James Cook University, Faculty of Medicine, Health \& Molecular Sciences, Graduate Research Scheme grants 2013 and 2014

Competing interests AM receives a personal income from Cancer Research UK via University College London. He has received travel funding, honorariums and consultancy payments from manufacturers of smoking cessation products (Pfizer Ltd, Novartis UK and GSK Consumer Healthcare Ltd). He also receives payment for providing training to smoking 
cessation specialists; receives royalties from books on smoking cessation and has a share in a patent of a nicotine delivery device.

Ethics approval Ethics approval was granted by the Aboriginal Health and Medical Research Ethics Committee and ratified by James Cook University and Southern Cross University Ethics Committees, and adheres to guidelines for Aboriginal and Torres Strait Islander research. ${ }^{61}$

Provenance and peer review Not commissioned; externally peer reviewed.

Data sharing statement Information regarding unpublished data is available by emailing the first author. The unpublished data comprise the results of the Smoking Risk Assessment Target and the Motivation to Stop Smoking Scale in the sample, referred to in our protocol. ${ }^{21}$

Open Access This is an Open Access article distributed in accordance with the Creative Commons Attribution Non Commercial (CC BY-NC 4.0) license, which permits others to distribute, remix, adapt, build upon this work noncommercially, and license their derivative works on different terms, provided the original work is properly cited and the use is non-commercial. See: http:// creativecommons.org/licenses/by-nc/4.0/

\section{REFERENCES}

1. Vos T, Barker B, Begg S, et al. Burden of disease and injury in Aboriginal and Torres Strait Islander Peoples: the Indigenous health gap. Int J Epidemiol 2009;38:470-7.

2. Commonwealth of Australia. National Tobacco Strategy 2012-2018 - a strategy to improve the health of all Australians by reducing the prevalence of smoking and its associated health, social and economic costs, and the inequalities it causes. Canberra: Commonwealth of Australia, 2012.

3. Australian Bureau of Statistics. 4727.0.55.006-Australian Aboriginal and Torres Strait Islander Health Survey: Updated Results, 2012-13. Canberra: Australian Bureau of Statistics, 2014. [updated 16 Jul 2014, 11 Oct 2014]. Australian Bureau of Statistics. 4727.0.55.006-Australian Aboriginal and Torres Strait Islander Health Survey: Updated Results.

4. Australian Institute of Health and Welfare. National Drugs Strategy Household Surveys Canberra: Australian Government; 2013 [cited 19 July 2014]. Available from: http://aihw.gov.au/alcohol-and-otherdrugs/ndshs/2013/tobacco/.

5. Hofhuis W, de Jongste JC, Merkus PJFM. Adverse health effects of prenatal and postnatal tobacco smoke exposure on children. Arch Dis Child 2003;88:1086-90.

6. Jaddoe VWV, Troe EJWM, Hofman A, et al. Active and passive maternal smoking during pregnancy and the risks of low birthweight and preterm birth: The generation R study. Paediatr Perinat Epidemiol 2008;22:162-71.

7. Robinson M, McLean NJ, Oddy $\mathrm{WH}$, et al. Smoking cessation in pregnancy and the risk of child behavioural problems: a longitudinal prospective cohort study. J Epidemiol Community Health 2010;64:622-9.

8. Rogers J. Tobacco and pregnancy. Reprod Toxicol 2009;28:152-60.

9. Gilman SE, Rende R, Boergers J, et al. Parental smoking and adolescent smoking initiation: an intergenerational perspective on tobacco control. Pediatrics 2009;123:e274-81.

10. Cornelius MD, Leech SL, Goldschmidt L, et al. Prenatal tobacco exposure: is it a risk factor for early tobacco experimentation? Nicotine Tob Res 2000;2:45-52.

11. US Department of Health and Human Services. The health consequences of smoking-50 years of progress: a report of the surgeon general. Rockville, MD: Public Health Service Office of the Surgeon General, 2014. http://www.surgeongeneral.gov/library/ reports/50-years-of-progress/50-years-of-progress-by-section.html

12. Doll R, Peto R, Boreham J, et al. Mortality in relation to smoking: 50 years' observations on male British doctors. BMJ 2004;328:1519.

13. OECD. OECD factbook 2013: economic, environmental and social statistics: moking. OECD Publishing, 2013.

14. Cancer Institute NSW. Aboriginal Smoking and Health Survey: Key findings: Cancer Institute NSW, 2014 [cited 2014]. http://www. cancerinstitute.org.au/publications/aboriginal-smoking-and-healthsurvey

15. Gould GS, Watt K, Stevenson L, et al. Developing anti-tobacco messages for Australian Aboriginal and Torres Strait Islander peoples: evidence from a national cross-sectional survey. BMC Public Health 2014:14:250.
16. Fishbein M, Ajzen I. Belief, attitude, attention and behaviour: an introduction to theory and research. Reading, MA: Addison-Wesley, 1975.

17. West R. Theory of addiction. Oxford: Blackwell, 2006

18. Caponnetto P, Polosa R. Common predictors of smoking cessation in clinical practice. Respir Med 2008;102:1182-92.

19. Vangeli E, Stapleton J, Smit ES, et al. Predictors of attempts to stop smoking and their success in adult general population samples: a systematic review. Addiction 2011;106:2110-21.

20. ITC. Talking About The Smokes Ontario, Canada: TC Policy Evaluation Project, 2014 [updated 3 June 2014; cited 3 August 2014]. http://www.itcproject.org/countries/australia/tats

21. Gould GS, Watt K, McEwen A, et al. Validation of risk assessment scales and predictors of intentions to quit smoking in Australian Aboriginal and Torres Strait Islander peoples: a cross-sectional survey protocol. BMJ Open 2014;4:e004887.

22. Gould GS, Watt $\mathrm{K}$, Cadet-James $\mathrm{Y}$, et al. Using the risk behaviour diagnosis scale to understand Australian Aboriginal smoking-a cross-sectional validation survey in regional New South Wales. Prev Med Rep 2015;2:4-9.

23. Bandura A. Health promotion by social cognitive means. Health Educ Behav 2004;31:143-64.

24. Wong NCH, Cappella JN. Antismoking threat and efficacy appeals: effects on smoking cessation intentions for smokers with low and high readiness to quit. J Appl Commun Res 2009;37:1-20.

25. Thomas DR. A general inductive approach for analyzing qualitative evaluation data. Am J Eval 2006;27:237-46.

26. Hussein $A$. The use of triangulation in social sciences research: can qualitative and quantitative methods be combined? J Comp Soc Work 2009;1:1-12.

27. Gould GS, Munn J, Avuri S, et al. "Nobody smokes in the house if there's a new baby in it": Aboriginal perspectives on tobacco smoking in pregnancy and in the household in regional NSW Australia. Women Birth 2013;26:246-53.

28. Australian Bureau of Statistics. Census of population and housing: socio-economic indexes for areas (SEIFA), Australia, 2011 (cat. no. 2033.0.55.001). Canberra: Australian Bureau of Statistics, 2013. [cited 8 July 2014]. http://www.abs.gov.au/websitedbs/censushome. nst/home/seifa2011

29. Oakes W, Chapman S, Borland R, et al. "Bulletproof skeptics in life's jungle": which self-exempting beliefs about smoking most predict lack of progression towards quitting? Prev Med 2004;39:776-82.

30. Johnston V, Thomas DP. Smoking behaviours in a remote Australian Indigenous community: the influence of family and other factors. Soc Sci Med 2008;67:1708-16.

31. Breslau N, Peterson EL. Smoking cessation in young adults: age at initiation of cigarette smoking and other suspected influences. $A m J$ Public Health 1996;86:214-20.

32. Thomas DP, Briggs V, Anderson I, et al. The social determinants of being an Indigenous non-smoker. Aust N Z J Public Health 2008:32:110-6.

33. Partos TR, Borland R, Siahpush M. Socio-economic disadvantage at the area level poses few direct barriers to smoking cessation for Australian smokers: findings from the International Tobacco Control Australian cohort survey. Drug Alcohol Rev 2012;31:653-63.

34. Gould GS, Munn J, Watters T, et al. Knowledge and views about maternal tobacco smoking and barriers for cessation in Aboriginal and Torres Strait Islanders: a systematic review and meta-ethnography. Nicotine Tob Res 2013;15:863-74.

35. Cosh S, Hawkins K, Skaczkowski G, et al. Tobacco use among urban Aboriginal Australian young people: a qualitative study of reasons for smoking, barriers to cessation and motivators for smoking cessation. Aust J Prim Health 2014. doi:10.1071/PY13157

36. Gilligan C, Sanson-Fisher RW, D'Este C, et al. Knowledge and attitudes regarding smoking during pregnancy among Aboriginal and Torres Strait Islander women. Med J Aust 2009;190:557-61.

37. Passey M, D'Este CA, Stirling JM, et al. Factors associated with antenatal smoking among Aboriginal and Torres Strait Islander women in two jurisdictions. Drug Alcohol Rev 2012;31:608-16.

38. Passey M, Gale J, Sanson-Fisher R. "It's almost expected": rural Australian Aboriginal women's reflections on smoking initiation and maintenance: a qualitative study. BMC Womens Health 2011;11:55

39. Dawson A, Cargo M, Stewart $\mathrm{H}$, et al. "I know it's bad for me and ye I do it": exploring the factors that perpetuate smoking in Aboriginal Health Workers-a qualitative study. BMC Health Serv Res 2012;12:102.

40. Passey ME, Sanson-Fisher RW, D'Este CA, et al. Tobacco, alcohol and cannabis use during pregnancy: clustering of risks. Drug Alcohol Depend 2014;134:44-50. 
41. Wood L, France K, Hunt K, et al. Indigenous women and smoking during pregnancy: knowledge, cultural contexts and barriers to cessation. Soc Sci Med 2008;66:2378-89.

42. Glover M, Kira A, Johnston V, et al. Australian and New Zealand Indigenous mothers' report respect for smoking bans in homes. Women Birth 2014.Published Online 8 Nov 2014. doi:10.1016/j. wombi.2014.09.004.

43. Clough AR, Robertson JA, MacLaren DJ. The gap in tobacco use between remote Indigenous Australian communities and the Australian population can be closed. Tob Control 2009;18:335-6.

44. Bond C, Brough M, Spurling G, et al. 'It had to be my choice' Indigenous smoking cessation and negotiations of risk, resistance and resilience. Health Risk Soc 2012;14:565-81.

45. Tsourtos G, Ward PR, Lawn S, et al. Is resilience relevant to smoking abstinence for Indigenous Australians? Health Promot Int 2015;30:64-76.

46. Passey M, Sanson-Fisher R, Gale J, et al. Tobacco, alcohol and cannabis use during pregnancy: views of pregnant Aboriginal women in NSW and ACT. Lismore: University Centre for Rural Health-North Coast, University of Sydney, 2011.

47. Twyman L, Bonevski B, Paul C, et al. Perceived barriers to smoking cessation in selected vulnerable groups: a systematic review of the qualitative and quantitative literature. BMJ Open 2014;4:e006414.

48. Curtis V. Why disgust matters. Philos Trans $R$ Soc Lond B Biol Sci 2011;366:3478-90.

49. Gough B, Antoniak M, Docherty G, et al. Smoking, self-regulation and moral positioning: a focus group study with British smokers from a disadvantaged community. Psychol Health 2013;28:1171-91.

50. Lennon A, Gallois C, Owen N, et al. Young women as smokers and nonsmokers: a qualitative social identity approach. Qual Health Res 2005;15:1345-59.

51. Fong G, Hammond D, Laux F, et al. The near-universal experience of regret among smokers in four countries: findings from the
International Tobacco Control Policy Evaluation Survey. Nicotine Tob Res 2004;6:341-51.

52. Rigotti NA, Wakefield M. Real people, real stories: a new mass media campaign that could help smokers quit. Ann Intern Med 2012;157:907-9.

53. Nunkuwarrin Yunti of SA Inc. Rewrite Your Story. South Australia: Nunkuwarrin Yunti; [cited 14 October 2014]. http://www. rewriteyourstory.com.au/

54. Lupton D. The pedagogy of disgust: the ethical, moral and political implications of using disgust in public health campaigns. Crit Public Health 2014;25:4-14.

55. Gould GS, Bittoun R, Clarke MJ. A pragmatic guide for smoking cessation counselling and the initiation of nicotine replacement therapy for pregnant Aboriginal and Torres Strait Islander smokers. J Smoking Cessation 2014. Published Online 31 Mar 2014. doi:10.1017/jsc.2014.3

56. Australian National Preventive Health Agency. Smoking and disadvantage evidence brief. Canberra: Commonwealth of Australia, 2013:6.

57. Carson KV, Verbiest MEA, Crone MR, et al. Training health professionals in smoking cessation. Cochrane Database Syst Rev 2012;5:CD000214.

58. Carson KV, Brinn MP, Peters M, et al. Interventions for smoking cessation in Indigenous populations. Cochrane Database Syst Rev 2012;1:CD009046.

59. Bonevski B. System-centred tobacco management: from 'whole-person' to 'whole-system' change. Drug Alcohol Rev 2014;33:99-101.

60. NSW Department of Health. NSW tobacco snapshot-May 2014. Sydney: NSW Health, 2014 [updated 9 July 2014; cited 27 September 2014]. http://www.health.nsw.gov.au/tobacco/pages/ default.aspx

61. NHMRC. Values and ethics: guidelines for ethical conduct in Aboriginal and Torres Strait Islander health research. Canberra, ACT: Commonwealth of Australia, 2003. 